\title{
Analysis on the Problems and Countermeasures of Agricultural Product E-commerce Development under the Background of Rural Revitalization
}

\author{
Guanghao Liu \\ School of Economics and Management, Zhejiang Ocean University, Zhoushan 316022, Zhejiang, China
}

\begin{abstract}
With the rapid development of science and technology in recent years, and the strong support of the Chinese government, the world's most extensive Internet area has been formed. In recent years, my country's E-commerce has developed very rapidly, which has promoted the development of rural E-commerce. The development of rural E-commerce has promoted the development of the rural economy, especially in the current country's rural revitalization strategy. The report of the 18th National Congress of the Communist Party of China stated: "Insist on focusing on the construction of national infrastructure and social development in rural areas, deepen the construction of new rural areas and poverty alleviation development, comprehensively improve rural production and living conditions, strive to increase farmers' income, and maintain a sustained and rapid income of farmers. increase". Rural E-commerce is a key link in the realization of the strategic goals of rural revitalization. Although my country's rural E-commerce development has made some outstanding achievements at this stage, in terms of the time period of rural E-commerce development, it is only in its infancy. There are bound to be many problems to be solved, and some problems in the treatment of the juvenile industry may make this industry disappear. This article is based on the rural revitalization strategy. This article explores the current problems in the development of rural E-commerce in my country, and proposes specific development paths to contribute to the further development of rural E-commerce.
\end{abstract}

Keywords: Rural revitalization, Agricultural products, E-commerce.

\section{Background and Significance}

The report of my country's 19th National Congress of the Communist Party of China clearly put forward the development strategy of rural revitalization. Local governments at all levels should actively analyze the development and actual situation of local rural E-commerce, because there will be some differences in each place, and sometimes these differences will Let this place become a feature, for example: some places are suitable for the growth of tea, other places are not, you can use this difference to develop. In this way, we propose a guarantee strategy that is in line with the development of local rural E-commerce, and improve my country's rural infrastructure construction, and make full use of Internet marketing methods and E-commerce technology to sell agricultural products, and through online marketing and promotion And other means to enhance the value of the product, in order to create its own unique agricultural product brand effect[1].

After the country issued documents on rural revitalization, the country began to carry out related construction, making the development environment of rural E-commerce in my country getting better and better. On the one hand, the scale of rural netizens has expanded rapidly. As of the end of the first quarter of 2020, the number of rural netizens nationwide has reached approximately 250 million; on the other hand, my country's new agricultural business entities have also developed rapidly in recent years. In 2019, there were more than 700,000 family farms and 2.201 million farmer cooperatives. According to the above data, with the development of economy and technological progress, China's rural areas will become a market with great potential[5].

Secondly, local governments at all levels in our country should use local characteristic E-commerce as a certain opportunity to expand their own rural E-commerce channels and E-commerce resources, build a rural E-commerce poverty alleviation platform that suits their locality, and issue related policies. Documents, so as to improve the brand and marketing of local agricultural products, and gradually optimize the rural-related agricultural product industry chain, and quickly build a logistics and transportation system for agricultural products between rural and urban areas, so that agricultural products can quickly enter the city, so as to obtain urban funds to carry out Related agricultural infrastructure construction and the development of rural E-commerce will also promote the sharing of rural and urban-related resources. After the country issued the plan for the rural revitalization strategy, the development environment in my country's rural areas has been the same day by day, and people's living standards have also been improved compared to the past. According to the "2020 National County Digital Agricultural and Rural E-commerce Development Report" published by the Information Center of the Ministry of Agriculture and Rural Affairs and the China International Electronic Commerce Center Research Institute, my country's new agricultural business entities are currently developing rapidly, with more than 700,000 family farms and farmers' cooperatives. There are 2.201 million households serving 60 million small farmers; at the same time, 52 national modern agricultural industrial parks and 298 strong agricultural industrial towns have been built. The improvement of the rural development environment has also created favorable conditions for the development of rural E-commerce in my country, and opened a path for the realization of rural revitalization.

Due to the previous mistakes in the relevant population policies, the existence of a large number of labor forces in our 
country, and these labor forces mainly exist in rural areas, leading to the current problem of employment difficulties. E-commerce can solve the employment difficulties faced by rural areas. Apart from agriculture, most of the farmers in our country choose to work in cities and towns, and a small part of them will stay in rural areas for production. However, with the development of economy and the progress of science and technology, the employment rate in my country's cities and towns has declined in recent years. Most farmers are also facing employment difficulties, and the emergence of E-commerce can effectively solve such problems. Secondly, the uniqueness of E-commerce plus the support of the current logistics system can help solve the problem of difficult agricultural product sales in rural areas. In the past, due to the imperfect road system between urban and rural areas and the relatively low level of interaction of related information, agricultural products produced in rural areas in my country faced a series of problems in marketing, such as high logistics costs, slow speed, inconvenient communication, and inaccessible information, etc. However, cities are also facing related problems such as high prices of agricultural products. But now the development of E-commerce is closely linked with logistics facilities, so it can solve some problems to a certain extent, fundamentally increase the marketing volume of our country's agricultural products and increase the income of farmers. Finally, E-commerce can form a product chain and accelerate the integration of the agricultural product industry chain. For example, the combination of online and offline E-commerce marketing models and the live broadcast of agricultural products can break through the restrictions on traditional sales of agricultural products and make related agricultural products Sales nationwide, so that it will not have geographic restrictions, so that a large number of fresh agricultural products can be better publicized and marketed.

\section{Related Concepts of Rural Revitalization and Rural E-commerce}

\subsection{The Concept of Rural Revitalization}

The rural revitalization strategy is the improvement and strengthening of the previous socialist new rural construction, which was put forward by China in the report of the 19th National Congress of the Communist Party of China. This is the first time that the relevant concepts and content of rural revitalization have been clearly stated. Someone has proposed rural revitalization a long time ago, but due to some factors, it has not been applied to the whole country. Up to now, the state has formally issued its definition to the whole country, allowing the whole country to implement it, which shows that our country attaches great importance to the "three rural" issues. The revitalization of the countryside requires that "industrial prosperity" replace the previous "production development", emphasizing that farmers should cultivate new industries that meet the new market based on the development of production and improve the related industrial system to make the rural areas better and the people prosperous. The economy is more prosperous; the "ecological livability" in the report refers to the need to guide the rural development of a green and environmentally friendly economy on the basis of solving the rural environment The environment, living environment, and ecological environment are more comfortable and beautiful, making the countryside a beautiful and harmonious place; replacing "management democracy" with "effective governance" means to handle the relationship between relevant cadres and most farmers. This is very important for related rural construction, and we must also work hard to coordinate and coordinate various interest relationships. If these are not handled properly, it may cause errors in the related rural governance system, and the emergence of problems is greater than those that are not. The problems that are well discovered are much better. The solution of the problems can make the relevant governance content more complete and make the entire governance process more effective. To achieve the prosperity of rural people, the living standards of farmers must reach the level of well-off society proposed by the country, so that farmers Life and survival are happier and more fulfilling; there are not too many changes in the rural customs and civilization in the document, but the specific content of the document will undergo relevant changes with the changes of the times and the environment. The rural revitalization strategy issued by the 19th National Congress of the Communist Party of China is to extend the previous governance of the living environment to the comprehensive governance of production, life, and ecological environment, so that the content included is more substantial. The release of the entire strategy makes the future of the village. The development prospects of the company have become clearer. Let farmers be full of hope in their hometown, contribute to their hometown, and give feedback for the strong support of the country.

\subsection{The Concept of Agricultural E-commerce}

E-commerce of agricultural products refers to the use of current relevant technical means under the open and broad network environment of the Internet, and non-interview-type exchanges between the transaction parties, so as to carry out the trading activities of agricultural products in space and time. It is the Internet The new path of technological and era changes is a new type of agricultural product sales model for the sales of agricultural products.

The circulation and sales process of traditional agricultural products in my country includes multiple levels of circulation links such as producers of agricultural products, wholesalers, and retail terminals. If the circulation of a thing is too complicated, it will usually cause many problems, such as information on both parties to the transaction. Poor circulation, inconvenient logistics, high logistics costs, etc. Because agricultural products have short shelf life and large seasonal changes, and compared to other products, they have high storage and transportation requirements. For example, cold chain insurance logistics is a very important part of it. The development and emergence of the Internet and its related technologies have just improved the current shortcomings of agricultural product E-commerce sales. With the development of the times, the circulation channels of agricultural products have now become the current multi-mode coexistence. The most common modes on the market now are the $\mathrm{O} 2 \mathrm{O}$ mode, 
B2B mode and B2C mode, each of which has its own characteristics.

\section{The Current Problems with Product E-commerce}

\subsection{Small Farmers have a Deep-rooted Consciousness and Fail to Pay Attention to the Brand}

Most people in rural areas have not been educated and have not had relevant information exchanges with big cities for a long time. As a result, farmers do not know how to operate in the development of related businesses. In addition, the countryside has been affected by the traditional small-scale peasant economy. Most of the farmers in Canada like to settle for the status quo, so they are very satisfied with their "one-mu three-quarter land". So when they are allowed to develop E-commerce and large-scale agricultural farming, even in a society where information exchange is so convenient now, they are also exposed to a lot of outside information, but they may still be reluctant to do it. For me from a rural background, I feel very deeply about this. People outside the countryside think it is relatively simple, but the countryside is very complicated, and the relationship between villagers is not as good as expected. Even though the state has announced the reform of the land transfer and land property rights system, most farmers are still unwilling to cooperate, because it harms their use and has limited scope for thinking and did not see the benefits. When some farmers start to make related changes, for example, when a farmer has contracted a piece of land to grow apples without growing grain, and this farmer has made a lot of profits that year. Then the whole village may be planted with apples in the next year. In terms of brands, farmers basically don't care. As a result, there are few well-known agricultural products brands in China. It is well known that the brand effect is very important, but the village has not carried out relevant construction in this area, and the homogeneity of agricultural products is serious, which will cause some good products to be sold according to the ordinary products on the market, and there is no way to reflect Word of mouth and brand effect[2]. There are still some good agricultural products brands in China. For example, Yangcheng Lake's hairy crabs are well-known throughout the country. They are also hairy crabs, but in terms of sales, Yangcheng Lake's purchases are quite expensive. This is the effect of the brand.

\subsection{The Construction of the Related Logistics System is not Perfect, and the Logistics Cost is Too High}

With the rapid development of the times, people have high requirements for everything, especially for the development of E-commerce. At the beginning, the operation of online shopping was not particularly simple and the logistics and transportation were slow. Now, you can shop at any time, and Seeing where the things you buy go to, most of the logistics time is 3-4 days. These advancements have put forward higher requirements for the E-commerce supporting logistics industry[9]. Based on the perishable and deteriorating characteristics of agricultural products, the shortcomings of traditional logistics systems are too obvious. Until now, most villages and towns in our country have started to have E-commerce logistics, but there are only a few in rural areas that may have logistics, and there is no relevant logistics base and relevant cold chain logistics, which leads to certain difficulties in the transportation of agricultural products. This is also due to my country's vast territory and large population, so that most of our farmers operate on a small scale and their residences are scattered. This will make most logistics companies unwilling to spend a lot of money to enter. If it enters, the logistics cost will also be greatly increased, which is extremely detrimental to farmers, but it also makes it inconvenient for farmers to send express delivery, which will hinder the development of agricultural products E-commerce. On the other hand, the profit of agricultural products itself is relatively low, and the cost of living has now increased, resulting in higher logistics costs. Therefore, farmers can only use small profits but quick turnover, but this will also reduce farmers' profits. There is also the imperfect standard of agricultural product logistics service, which hinders the development of rural E-commerce. Logistics is a very important link in the expansion of rural E-commerce business. Related logistics companies need to have a set of related standardized procedures for packaging related agricultural products for their protection of agricultural products, so that the agricultural product logistics service system can be standardized, for consumers it is also extremely convenient and protects the product from harm, thus making both parties happy. However, from the current rural E-commerce business, it can be seen that in some rural areas, even the logistics system is not complete, and it is impossible to establish agricultural product logistics service standards. As a result, rural E-commerce customers cannot obtain agricultural product protection, which hinders the development of agricultural product E-commerce. Is not conducive to the implementation of rural revitalization and the prosperity of rural people[10].

\subsection{The Loss of Rural Population, the Lack of E-commerce Talents}

China is now the most populous country in the world, and most of them are farmers. However, due to the gap between agriculture and industry, there are also its own drawbacks. As a result, the population now engaged in agriculture has drastically decreased. Most of the rural people enter the cities to work. As a result, those who are now at home in the rural areas are the elderly, and there is a lack of young adults. People are the foundation of a foothold. In the current social environment, the lack of highly educated talents is detrimental to the development of any industry. The cultural education level of most agricultural producers in my country is mainly concentrated in elementary and junior high schools, and some do not even go to school. Yes, only write your own name. These people's understanding and acceptance of the new concepts of modern agricultural production and management are slower than those of higher education, and their ability to apply new technologies is relatively poor. Most agricultural producers have difficulty in their own conditions because they have not received relevant education. Meet the current 
E-commerce requirements for people[6]. Although my country's higher education has developed rapidly and many relevant talents have been cultivated, they will stay in the city for development. For them, the city has more opportunities. Compared with cities, rural areas are subject to many constraints such as job prospects and wages. Most of the talents trained by the state are unwilling to come to rural areas for development. However, with the vigorous development of rural E-commerce, rural areas will be transformed, economically and environmentally. Changes will bring about a large number of rural E-commerce talent gaps[11].

\subsection{Insufficiency of the Quality and Safety System Related to Agricultural Products}

In the traditional sale of agricultural products, most sellers generally sell the agricultural products in kind in the farmers' markets and supermarkets, which can be seen and touched by consumers. But what consumers don't know is that the agricultural products that can enter these places will definitely undergo food quality and safety inspections, which can prove that these foods are safe[3]. But nowadays, people's requirements for agricultural products are becoming higher and higher, such as: green pollution-free, pure natural, organic vegetables and so on. But now the development of E-commerce has eliminated the traditional advantages. Both parties in a transaction can only communicate through mobile terminals. Consumers can't see the real object, and can only understand it through pictures and introduced information. Generally, consumers do not know about quality inspections, so most E-commerce sellers do not have relevant inspection certificates, and the platform will not conduct inspections. The country has not issued relevant policy requirements in this regard. But the result of this is that the lack of related processes may cause some bad consequences, which are not good for both parties in the transaction. Eventually, it may hinder the development of agricultural products, causing consumers to distrust related products.

\section{Countermeasures to Solve the Problem of Agricultural Products E-commerce}

\subsection{Cultivate New Farmers and Establish Brand Awareness}

In order to cultivate people who meet the needs of modern agricultural production, the government must play an important role in it. The current information exchange is no longer a problem. The important thing is to change the small peasant concepts that exist in the consciousness of the rural people. The role of the government comes out. Farmers still believe in government propaganda. This propaganda can guide farmers to break the conservative and self-sufficient "small farmer consciousness", and regularly organize local rural youth, farmers and industries in a planned way. Cooperative leaders and other groups participate in new-type professional farmer training, and publicize the current state support in this area, so as to contribute to the cultivation and reserve of reserve talents for agricultural and rural development[7]. There is also the branding of agricultural products. The government should speed up the establishment of a product standard system for local agricultural products; give full play to the local government's role in market supervision in terms of agricultural product quality and brands, and timely understand and grasp the high-quality agricultural products in the region. Product categories, by integrating the upstream and downstream of the industrial chain, casting local specialty agricultural products brands, developing an integrated process model for farmers, online stores, and enterprises, and enhancing the brand influence of local specialty products through standardization and branding, and becoming an agricultural producer Reduce the risks in agricultural production, increase the added value of specialty agricultural products brands, and increase farmers' income[15].

\subsection{Speed up the Construction of Logistics System and Reduce Costs}

First, each local government should give full play to its leading role of the government, combine the actual situation of the local rural area in the entire operation, and analyze the local agricultural product E-commerce business with huge potential and development through relevant big data. The prospects are broad, and related investment promotion will be carried out through a series of policy documents, etc., to promote the construction of a large number of logistics distribution centers in certain rural areas, to ensure that some large-scale agricultural households can have sufficient logistics resources within a certain period of time Carry out logistics distribution. If you want to get rich, build roads first. Therefore, local governments should allocate a large amount of money to road construction to ensure the smoothness of roads, so as to improve the logistics resources in rural areas, increase the circulation of agricultural products, and ensure the development of agricultural E-commerce. Second, the government should cooperate with farmers when negotiating with logistics companies, requiring that the delivery price of agricultural products should not be the same as ordinary products. In this way, agricultural products that are not profitable in themselves will eventually make farmers obtain less income[8]. It is certainly impossible for farmers and logistics companies to talk about it. Therefore, the government may make adjustments in the middle and make it easier to reduce the logistics cost of agricultural products. There is also communication with logistics companies for standardized packaging of agricultural products. After agricultural products are standardized, they will be beneficial in both transportation and sales. For farmers, they can ensure the integrity of goods and establish standards; it is more convenient for transportation companies. Transportation; for consumers to be satisfied with the product.

\subsection{Introduce and Train E-commerce-related Talents}

To improve the lack of professional talents in rural areas, we can start from the following aspects: First, local governments should promote rural E-commerce through encouragement, encourage young groups such as college students to return to their hometowns to start businesses, and adopt a series of 
policy welfare supports college students' entrepreneurial work, allowing them to see the advantages of their hometown[13]. Second, the local government should establish a sound talent introduction system, break the limitations of the original traditional system, and expand the channel for the input of professional talents, such as directly from major universities, other enterprises, and professional training institutions. For example, rich places such as Jiangsu and Zhejiang have introduced many policies to attract college students and other young talents to stay with them[14]. Third, localities can use some professional training institutions to train some young and middle-aged people into talents that are in line with the development of E-commerce within a certain period of time[4].

\subsection{Establish a Relatively Complete Agricultural Product Safety Mechanism}

With the continuous development of society, people's requirements for just remembering health are getting higher and higher, and the country is also reforming and improving in this regard. Therefore, the food safety issue of the society has received extensive attention from people, and the agricultural products want to continue to be healthy. In addition to relevant technical support, the most fundamental thing for development is to ensure the quality of agricultural products[12]. Therefore, it is necessary to guide farmers to reasonably control the dosage of pesticides and to select qualified pesticides produced by regular manufacturers, and to randomly check the production standards and product quality of pesticide factories to solve the problem from the root cause. Secondly, in the deep processing of related agricultural products, fresher foods should be selected for processing, and stale foods should not be processed, but sold on the market. If qualified agricultural product producers can set up their own processing plants, they can also solve some employment problems and help other unqualified agricultural product producers to process their products. Finally, it carries out exclusive maintenance and regular inspections to ensure the quality of its food and is responsible for itself and others.

\section{Conclusion}

The development of science and technology and the implementation of the rural revitalization strategy have brought new opportunities for the development of rural E-commerce and made a huge contribution to the development of rural areas. At the same time, the rapid development of rural E-commerce has also promoted the flow of resource elements between rural and urban areas, so that they can get the resources they want between the two, and promote the development of agricultural E-commerce, in order to achieve rural revitalization. Injecting a lot of vitality and resources has provided some impetus to promote the resolution of the three rural issues. Although the development of rural E-commerce is still relatively rudimentary, the development of E-commerce for many other products has solved many problems for E-commerce of agricultural products. Therefore, E-commerce of agricultural products is standing on the shoulders of giants, and agricultural products have begun to go online. The under-integration model has advanced to adapt to the new changes in consumer demand, carry out research and development of the diversity of agricultural products, and increase quality products and services through multiple channels, and it is more closely integrated with consumption upgrades, implementation of rural revitalization strategies, and poverty alleviation. To get rid of the restrictive factors in the development of rural E-commerce, and support the development of new models.

\section{References}

[1] Liu Ling'e. Analysis of the Development Model of E-commerce in Counties and Rural Areas[J]. China Business Review, 2020 (15): 38-39.

[2] Deng Xia. Thoughts on Rural E-commerce Boosting Rural Development: Taking Yunfu City, Guangdong Province as an Example $[\mathrm{J}]$. Guangdong Economy, 2020(7): 84-89.

[3] Zhong Yibo. Study on the Stage Division and Key Factors of Rural E-commerce Development[J]. China Collective Economy, 2020(20): 113-115.

[4] Wei Yan'an. How to Promote the Poverty Alleviation Through E-commerce[J]. The Agricultural Staff, 2018(08): 26-27.

[5] Wang Junling. China's Online Retail Sales in the First Three Quarters Exceeded 7 Trillion Yuan[N]. People's Daily Overseas Edition, 2019-11-04 (04).

[6] Sheng Qianqian. The Opportunities and Challenges of China's Rural E-commerce Development under the Background of Targeted Poverty Alleviation[J]. Hubei Agricultural Sciences, 2017(22): 4374-4377.

[7] Zhou Bin, Li Xin, Hu Haijing, et al. Discussion on Sustainable Development of Rural E-commerce under the Background of Rural Revitalization Strategy[J]. Shopping Mall Modernization, 2018(22): 13-15.

[8] Cheng Qiyuan. Research on the Countermeasures to Promote the Development of Guangxi Rural E-commerce under the Background of Rural Revitalization Strategy[J]. Economic and Social Development, 2018 (5): 25-30, 77.

[9] Li Lu, Li Jianfang. Exploration of the Path of Efficient Development of Rural E-commerce under the Background of Rural Revitalization Strategy[J]. Value Engineering, 2019(6): 62-64.

[10] Su Cui. Research on the Development of E-commerce Logistics of Agricultural Products in Remote Areas[J]. Logistics Technology, 2021, 40(03): 25-28.

[11] Xie Yunxuan. Development Status and Countermeasures of Hubei Rural E-commerce Industry[J]. Cooperative Economy and Technology, 2021(05): 90-91.

[12] Xia Lili. Research on the Development of Agricultural Products E-commerce in Cangzhou[J]. Cooperative Economy and Technology, 2021(04): 86-87.

[13] Hong Wensheng. Discussion on Live Broadcast of Rural Cadres to Bring Goods to Promote Rural Revitalization[J]. Modern Marketing (Business Edition), 2021(01): 84-86.

[14] Wang Sihan. Research on the Talent Training Model of Rural E-commerce in Higher Vocational Colleges under the Background of Rural Revitalization-Taking 
Tongren Vocational and Technical College as an Example[J]. Industry and Technology Forum, 2020, 19(23): 177-178.

[15] He Jianing, Ma Kun. The Development Status and Improvement Suggestions of Rural E-Commerce in Tongzi County, Guizhou[J]. Heilongjiang Grain, 2020(11): 68-69+72.

\section{Author Profile}

Guanghao Liu (1996- ), Postgraduate of the School of Economics and Management, Zhejiang Ocean University. Born in Huangchuan County, Henan Province, his professional name is agricultural management. 